\title{
Diels-Alder reactions of beta-vinyl-meso-tetraphenylporphyrin with quinones
}

\author{
Maria A. F. Faustino, Maria G. P. M. S. Neves, Augusto C. Tomé, Artur M. S. Silva, and \\ José A. S. Cavaleiro* \\ Department of Chemistry, University of Aveiro, 3810-193 Aveiro, Portugal \\ E-mail: jcavaleiro@dq.ua.pt
}

\section{Dedicated to Professor José Elguero on his $\mathbf{7 0}^{\text {th }}$ anniversary and to Professor Pedro Molina on his $60^{\text {th }}$ anniversary}

(received 30 Dec 04; accepted 15 Apr 05; published on the web 19 Apr 05)

\begin{abstract}
Ni(II)-2-Vinyl-5,10,15,20-tetraphenylporphyrin reacts with 1,4-naphthoquinone and 1,4benzoquinone to afford mixtures of rigid porphyrin-quinone derivatives with extended $\pi$ systems. The structures of these novel compounds were deduced from detailed NMR experiments.
\end{abstract}

Keywords: Diels-Alder reactions, cycloadditions, cyclizations, porphyrins, benzoporphyrins, quinones, structural elucidation, NMR

\section{Introduction}

The synthesis of new porphyrin derivatives by structural modification of simpler porphyrins is a valuable alternative to the total chemical synthesis of these compounds. Knowing the versatility and selectivity of pericyclic reactions in organic synthesis, it is not surprising that these types of reactions have been applied in the chemical modification of porphyrins. In fact, it has been shown that porphyrins can participate in a range of pericyclic reactions, namely Diels-Alder reactions, 1,3-dipolar cycloadditions, 1,5-electrocyclizations and cheletropic reactions. ${ }^{1}$ In these reactions the porphyrin macrocycle can participate as the $2 \pi$ - or the $4 \pi$ - electron component. In the specific case of the protoporphyrin-IX type compounds (meso- unsubstituted porphyrins containing two vinyl groups in the $\beta$ - positions), their use as dienes in Diels-Alder reactions has been the subject of several studies, mainly in reactions with tetracyanoethylene (TCNE) and dimethyl acetylenedicarboxylate (DMAD) ${ }^{2-6}$ Later, we have also shown that 2-vinyl- mesotetra-arylporphyrins can also participate as dienes in Diels-Alder reactions. ${ }^{7-10}$ For example, nickel(II)- 2-vinyl-5,10,15,20-tetraphenylporphyrin 1 reacts with TCNE to afford the expected 
[4+2] cycloadduct $\mathbf{2}$ and also the [2+2] cycloadduct $\mathbf{3}$ (Scheme 1). ${ }^{7}$ The porphyrin $\mathbf{1}$ also reacts with DMAD to give two main products: the (green) chlorin $\mathbf{4}$ and the (red) benzoporphyrin $\mathbf{5}^{8}$ Oxidation of chlorin 4 with 2,3-dichloro-5,6-dicyano-1,4-benzoquinone (DDQ) affords the benzoporphyrin 5 in a quantitative yield.
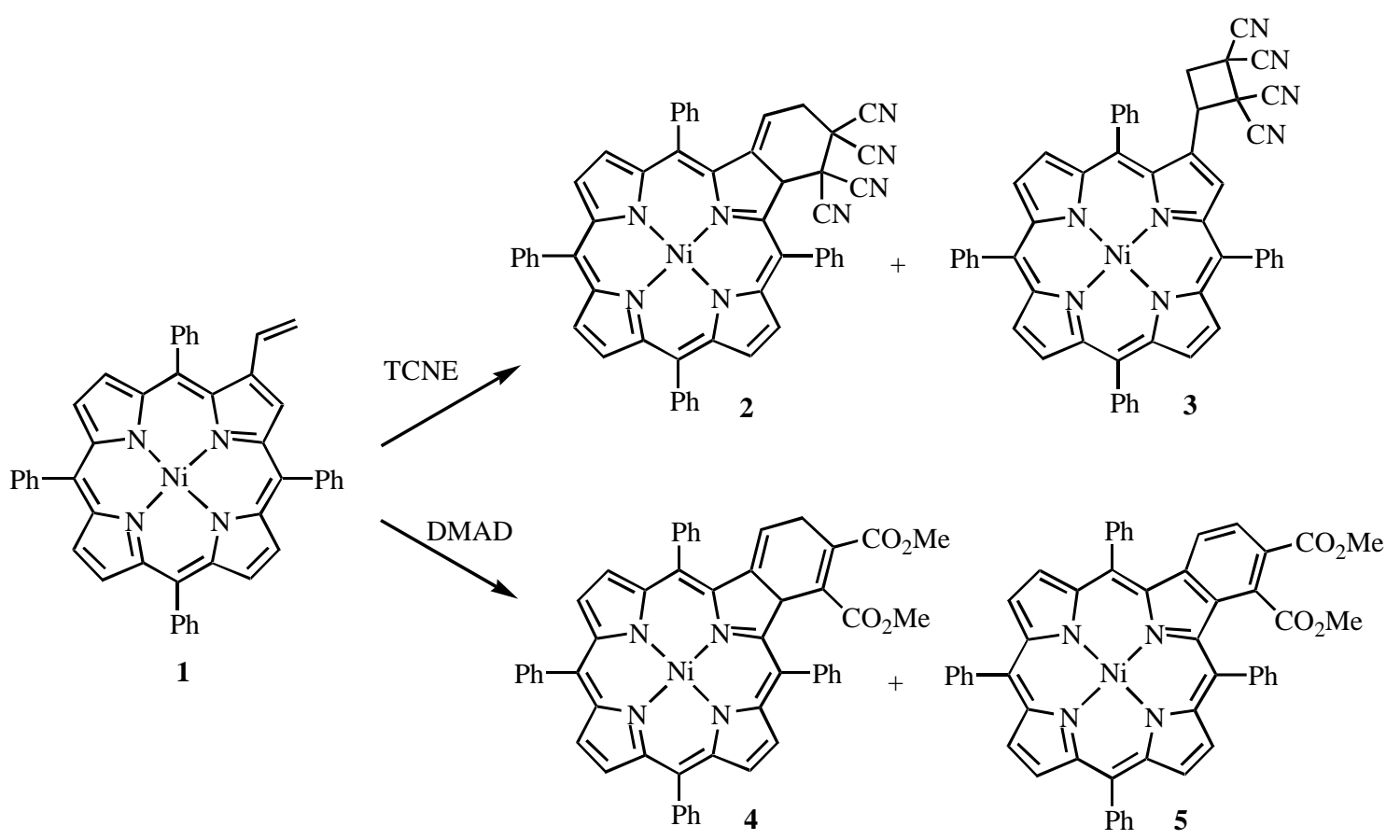

\section{Scheme 1}

In this paper we describe the reaction of porphyrin 1 with 1,4-naphthoquinone and 1,4benzoquinone. In both cases, the Diels-Alder reaction occurs but the adducts are converted into other porphyrin-quinone derivatives (Schemes 2 and 3). The resulting compounds are quite promising since there is great interest in porphyrins containing quinone moieties. Porphyrinquinone compounds are important model systems for photosynthetic electron-transfer studies, ${ }^{11-}$ ${ }^{15}$ or as anticancer agents, ${ }^{16}$ and others can be used as fluorescent chemosensors, ${ }^{17,18}$ or as catalysts in oxidation reactions of organic molecules. ${ }^{19}$ Apart from scarce exceptions, ${ }^{20-22}$ the porphyrin-quinone molecules already prepared have the quinone moiety linked to a mesoposition of the porphyrin macrocycle. However, the compounds we now describe contain that structural feature incorporated in a rigid extended $\pi$-system, and can potentially be used as chemical and electrochemical controllable switches. ${ }^{20 a}$

\section{Results and Discussion}

The reaction of porphyrin 1 with 1,4-naphthoquinone ${ }^{9}$ was carried out in refluxing toluene, under a nitrogen atmosphere, with an excess of 1,4-naphthoquinone (five equivalents). TLC of the 
reaction mixture shows some starting porphyrin and three products (Scheme 2). The compounds were separated by preparative TLC (silica gel) using toluene as eluent. Compounds 6a and 7a have quite similar $\mathrm{R}_{\mathrm{f}}$ values and great care must be taken to separate them. The product with lower $R_{\mathrm{f}}$ value was identified as the hydroxylated compound $\mathbf{8}$. When treated with $10 \%$ trifluoroacetic acid in chloroform, compound $\mathbf{8}$ was converted into the porphyrin derivative 7a in good yield (85\%). Demetallation of $\mathbf{6 a}$ with $10 \%$ sulfuric acid in trifluoroacetic acid afforded the corresponding free porphyrin $\mathbf{6 b}$ in quantitative yield.

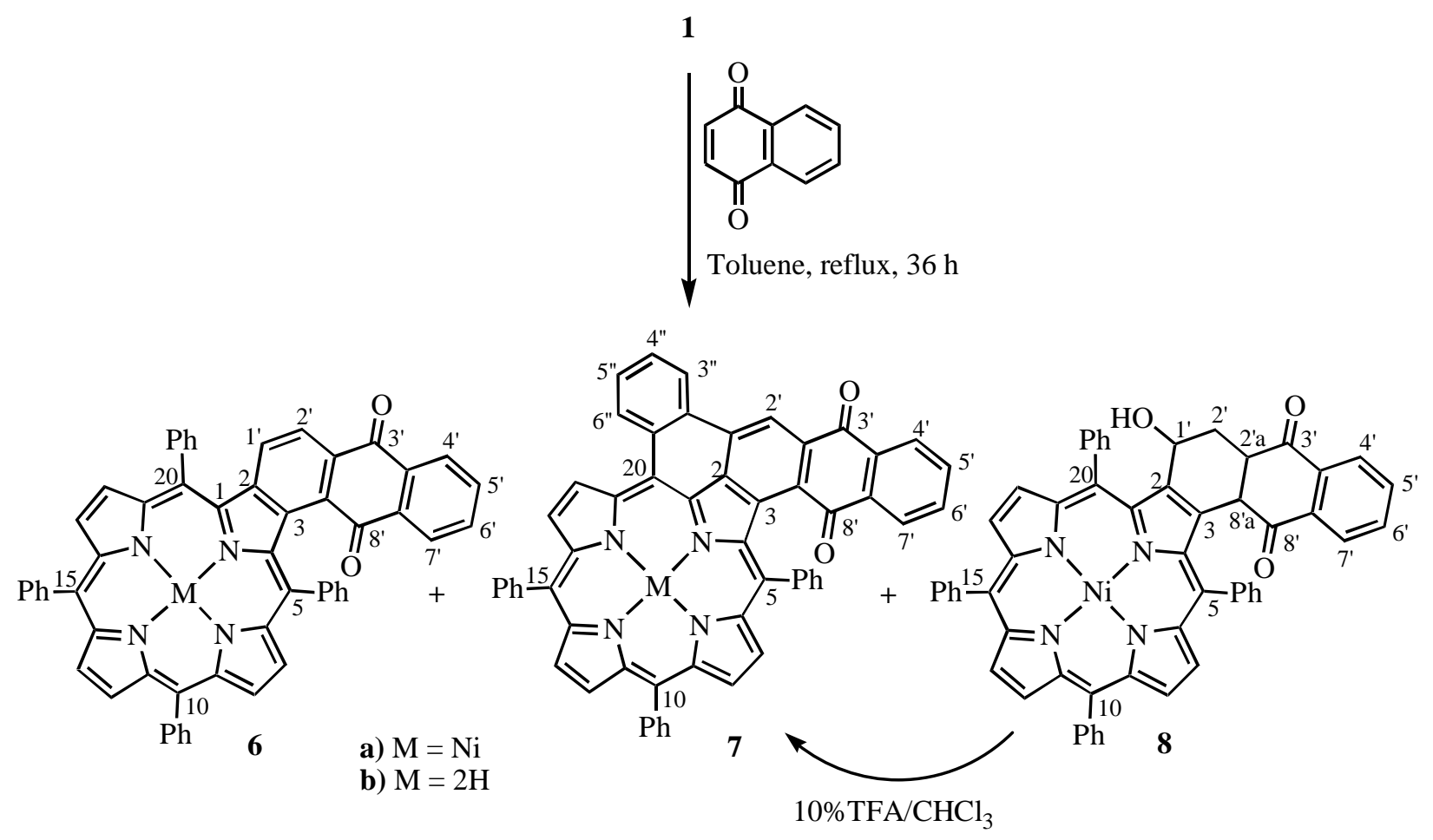

\section{Scheme 2}

After the conclusion of our work, Matsumoto's group reported the reaction of porphyrin $\mathbf{1}$ with a range of dienophiles, including 1,4-naphthoquinone. ${ }^{23,24}$ These authors pointed out that, under reaction conditions similar to those we have used (refluxing toluene for 2 days), porphyrin 1 reacts with 1,4-naphthoquinone to give a single product in $76 \%$ yield. The product was identified as 6a. However, neither the UV-Vis nor ${ }^{1} \mathrm{H}$ - NMR spectra reported for this compound are identical to those we have obtained. If we compare the UV-Vis spectrum reported by the Matsumoto's group with the spectra of our compounds 6a and 7a (Table 1), we can say that their compound cannot be 6a, since it does not show the absorption band at $565 \mathrm{~nm}$ (Figure 1). Their $\mathrm{UV}-\mathrm{Vis}$ spectrum seems to identical to that of $7 \mathbf{a}$ but the ${ }^{1} \mathrm{H}$ - NMR spectrum they reported is not consistent with that structure! Probably their compound “6a” is a mixture of $\mathbf{6 a}$ and $\mathbf{7 a}$. In their paper, these authors say the following: “The naphthoquinone adduct "6a” appears to be a very crowded and interesting structure, e.g., the visible spectrum is markedly different from those of 
other adducts (red shifted, broadened, intensification of the far-red band). Presumably this is indicative of out-of-plane distortion and/or extension of the system." ${ }^{24}$ Probably the red shifting, broadening, and intensification of the far-red band they observed is due to the presence of the polycyclic porphyrin 7a.

Table 1. UV-Vis spectra of porphyrin derivatives $6 \mathbf{a}$ and $7 \mathbf{a}$

\begin{tabular}{ccl}
\hline \multirow{2}{*}{ Compound } & \multicolumn{2}{c}{$\lambda / \mathrm{nm}(\log \varepsilon)$} \\
\cline { 2 - 3 } & Soret band & \multicolumn{1}{c}{ Q bands } \\
\hline Matsumoto’s ${ }^{24}$ “6a”a & 448 & $590(4.06), 640(4.16)$ \\
6a $^{\text {b }}$ & 437 & $565(3.94)$ \\
7a $^{\text {b }}$ & 448 & $593(3.51), 644(3.54)$ \\
\hline
\end{tabular}

${ }^{\mathrm{a}}$ Recorded in $\mathrm{CH}_{2} \mathrm{Cl}_{2}$. ${ }^{\mathrm{b}}$ recorded in $\mathrm{CHCl}_{3}$.

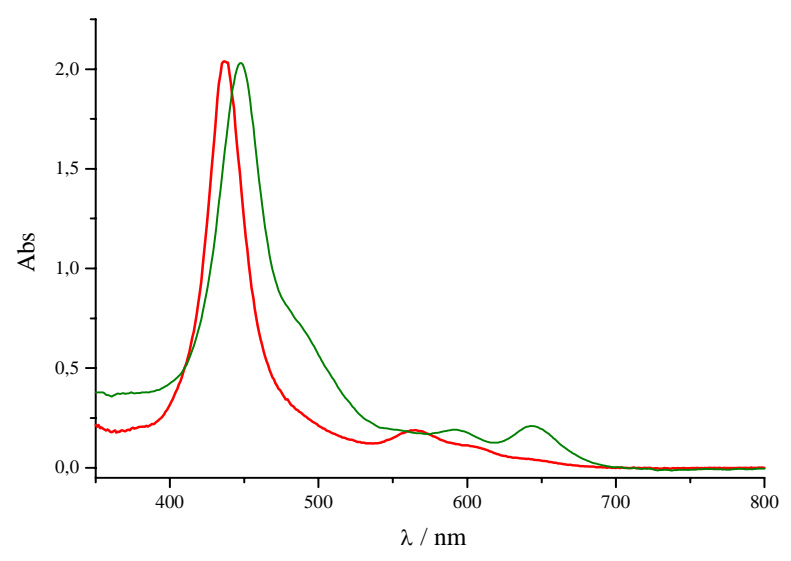

Figure 1. UV-Vis spectra of compound 6a (red line) and 7a (green line) in chloroform.

The main features of the ${ }^{1} \mathrm{H}$ - NMR spectrum of compound 7a are the singlet at $\delta 9.77 \mathrm{ppm}$ and a series of eight doublets and one AB- spin system between $\delta 9.33$ and 8.05 ppm (Figure 2). Four of these doublets and the AB- spin system are due to the resonance of the $\beta$-pyrrolic protons. The analysis of the COSY spectrum seems to indicate that the doublets at $\delta 9.05$ and $8.61 \mathrm{ppm}$ correspond to the resonance of two protons of an ABCD spin system. In the NOESY spectrum, a NOE cross-peak was observed between the singlet at $\delta 9.77 \mathrm{ppm}$ and the doublet at $\delta 9.05 \mathrm{ppm}$. In a 1D selective INEPT experiment, upon irradiation of the singlet at $\delta 9.77 \mathrm{ppm}$ the resonances of a carbonyl- carbon ( $\delta 184.7 \mathrm{ppm})$ and of two quaternary carbons were observed (Figure 3). In another 1D selective INEPT experiment, the same carbonyl- carbon resonance was observed upon irradiation of the doublet at $\delta 8.37 \mathrm{ppm}$. All these data are only compatible with the structure of the polycyclic compound $7 \mathbf{a}$. 


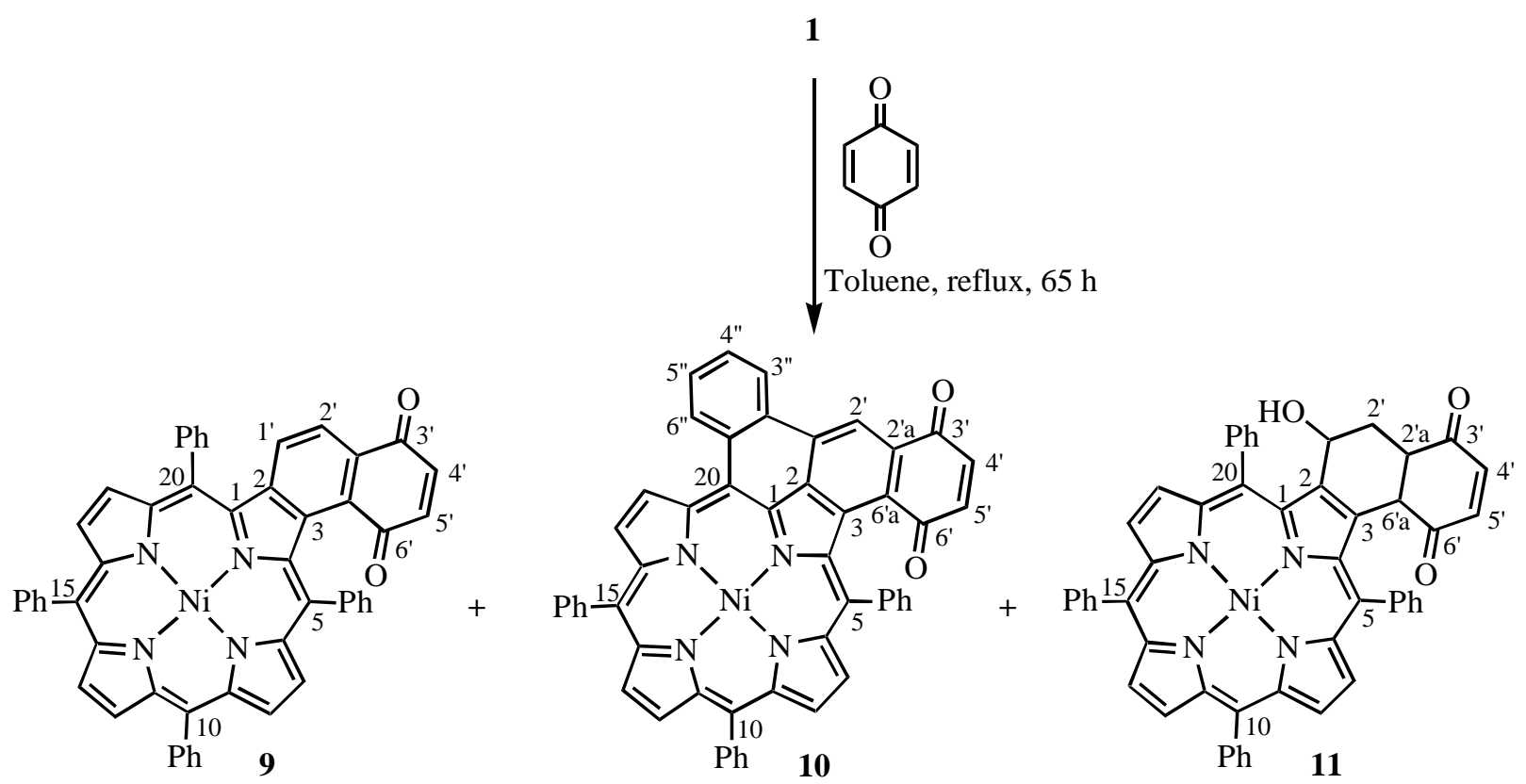

Scheme 3

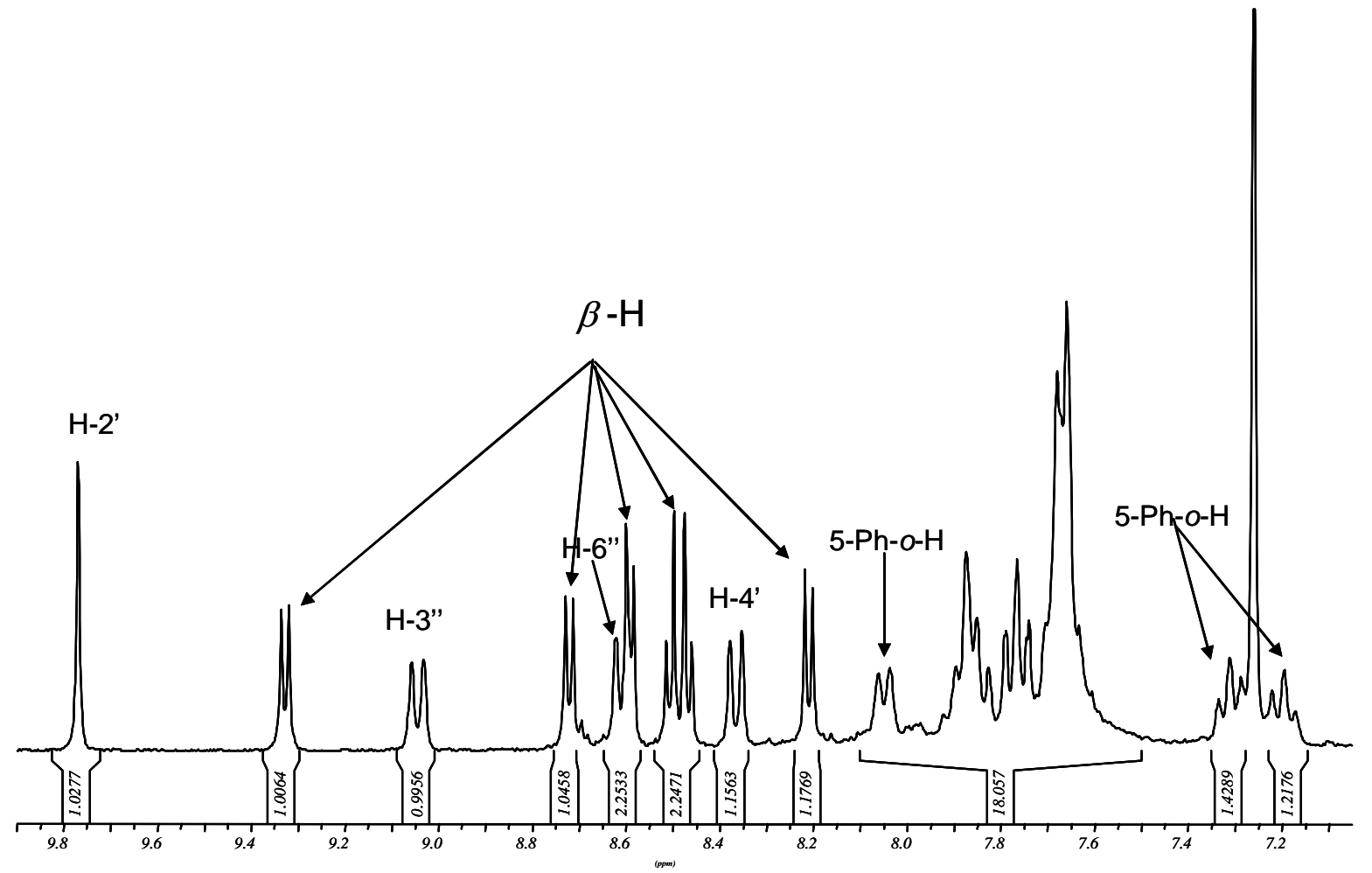

Figure 2. Part of the ${ }^{1} \mathrm{H}$ NMR spectrum of compound 7a. 

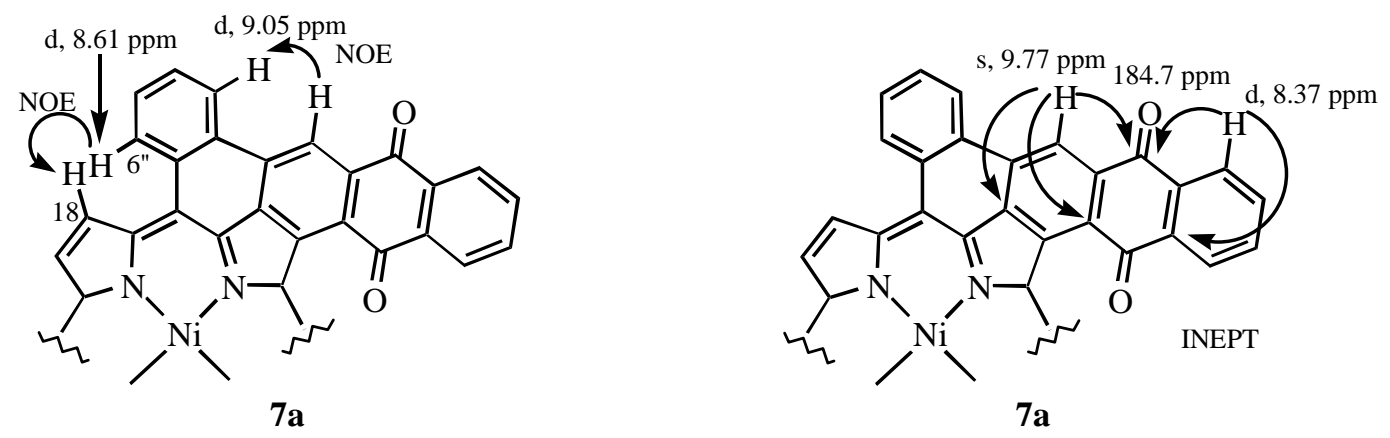

Figure 3. Main NOE cross peaks and 1D selective INEPT connectivities.

The NOE cross-peak between the signal of $\mathrm{H}-6$ ', and that of one $\beta$-pyrrolic proton at $\delta 9.33 \mathrm{ppm}$, allowed us to assign it to the resonance of $\mathrm{H}-18$, and that at $\delta 8.72 \mathrm{ppm}$ to $\mathrm{H}-17$ (COSY). All the other proton- and carbon- resonance assignments were made with the aid of COSY, NOESY and HETCOR NMR spectra.

The analysis of the ${ }^{1} \mathrm{H}$ - and COSY- NMR spectra of compound $\mathbf{6 a}$ allowed us to assign the resonances of the six $\beta$-pyrrolic protons (six doublets, at $\delta 8.73,8.68,8.62,8.54,8.52$ and $8.17 \mathrm{ppm}$ ) and of six protons of the naphthoquinone moiety. The resonances of $\mathrm{H}-2$ ' and $\mathrm{H}-1$ ' appear as doublets at $\delta 8.29$ and 7.33 ppm, respectively. The resonance of $\mathrm{H}-2$ ' is more deshielded than $\mathrm{H}-1$ ' owing to the anisotropic deshielding effect of the 3'-carbonyl group. The ABCD spin system of protons H-4', H-5', H-6' and H-7' was also assigned with the aid of the COSY spectrum. The resonances of $\mathrm{H}-4^{\prime}$ ' and $\mathrm{H}-7^{\prime}$ ' are also more deshielded then those of $\mathrm{H}-5^{\prime}$ and H-6' owing to the anisotropic deshielding effect of the 3'- and 8'- carbonyl groups.

The NMR spectrum of compound 8 shows resonances corresponding to six $\beta$ - pyrrolic protons, twenty meso- phenyl protons and four protons from the naphthoquinone moiety. In the aliphatic region of the spectrum we observe six proton resonances. From the ${ }^{13} \mathrm{C}$ - NMR-DEPT experiments it was possible to conclude that compound $\mathbf{8}$ has only one methylenic carbon ( $\delta 34.8 \mathrm{ppm}$ ) and three methynic carbons ( $\delta 44.9$, 50.1 and $62.0 \mathrm{ppm}$ ). The analysis of the HETCOR and COSY spectra allowed the assignment of all these aliphatic proton and carbon resonances; H-1' ( $\delta 5.14 \mathrm{ppm})$ and C-1' ( $\delta 62.0 \mathrm{ppm})$ are the most deshielded ones, owing to their benzylic-type character.

We also extended this work to the reaction of porphyrin 1 with 1,4-benzoquinone (Scheme $3)$. This reaction afforded the same type of compounds as obtained in the reaction with 1,4naphthoquinone: the naphtho[1,2-b]porphyrin $\mathbf{9}$, the polycyclic derivative $\mathbf{1 0}$, and the hydroxy derivative $\mathbf{1 1}$ (main fraction). ${ }^{10}$ The analysis of the ${ }^{1} \mathrm{H}$ - NMR spectrum of compound $\mathbf{1 0}$ allowed us to conclude that it should have a structure similar to 7. The resonance of H-2' appears as a singlet at $\delta 9.62 \mathrm{ppm}$, and $\mathrm{H}-3$ ', as a doublet at $\delta 9.10 \mathrm{ppm}$; a close proximity between both protons is indicated in the NOESY spectrum. The COSY spectrum allowed the assignment of all resonances of the ABCD spin system, starting from that of $\mathrm{H}-3$ ', ' The resonances of $\mathrm{H}-4$ ' and $\mathrm{H}-$ 5' appear as two doublets at $\delta 6.47$ and $6.92 \mathrm{ppm}(J=10.4 \mathrm{~Hz})$. A careful analysis of the 
NOESY spectrum of $\mathbf{1 0}$ allowed the unequivocal assignment of $\mathrm{H}-18$ ( $\delta 9.40 \mathrm{ppm})$, since this resonance presents a NOE cross-peak with that of H-6’' $(\delta 8.70 \mathrm{ppm})$.

In the ${ }^{1} \mathrm{H}$ - NMR spectrum of compound 9, in conjunction with the COSY spectrum, we can assign the signals corresponding to the resonances of: (a), six $\beta$-pyrrolic protons, appearing as doublets at $\delta$ 8.72, 8.67, 8.63, 8.53, 8.51 and 8.25 ppm, (b), twenty meso- phenyl protons, which appear as a multiplet at $\delta 7.54-7.97 \mathrm{ppm}$, and (c), four protons of the naphthoquinone moiety. These appear in two groups of two doublets each, one due to $\mathrm{H}-1^{\prime}$ and $\mathrm{H}-2$ ' ( $\delta 7.28$ and $8.06 \mathrm{ppm}$ ) and the other corresponding to H-4' and H-5' ( $\delta 6.24$ and $6.67 \mathrm{ppm}$ ).

The ${ }^{1} \mathrm{H}$ - NMR spectrum of the hydroxylated derivative $\mathbf{1 1}$ is very similar to that of compound 8. It shows signals in the aromatic and aliphatic regions. The ${ }^{13} \mathrm{C}-\mathrm{NMR}-\mathrm{DEPT}$ experiments allowed the identification of one methylenic ( $\delta 34.9 \mathrm{ppm})$ and three methynic ( $\delta$ 44.7, 49.8 and $61.7 \mathrm{ppm}$ ) carbon resonances in the aliphatic region. With a careful analysis of the COSY and HETCOR spectra it was possible to assign all the aliphatic proton and carbon resonances. In a 1D- selective INEPT experiment, upon irradiation of the resonance of H-6'a ( $\delta 4.33$ ppm), the resonances of C-5' ( $\delta 138.3$ ppm), C-6’ ( $\delta 198.0 \mathrm{ppm})$, and C-2'a ( $\delta 44.7 \mathrm{ppm})$ were observed. These results and the analysis of the HETCOR spectrum allowed the unequivocal assignment of H-4' ( $\delta 6.63 \mathrm{ppm})$ and $\mathrm{H}-{ }^{\prime}$ ' $(\delta 6.51 \mathrm{ppm})$ and to confirm that of $\mathrm{H}-2$ 'a $(\delta 3.84$ ppm). The resonance of the carbonyl carbon C-3’ was then attributed to the signal at $\delta 201.1$ ppm.

\section{Mechanistic considerations}

As mentioned above, the expected [4+2] chlorin adducts were not obtained and instead dehydrogenated and hydroxylated compounds were isolated. It is known that quinones are excellent agents in the dehydrogenation of hydroaromatic compounds; the dehydrogenation probably occurs by the transfer of a hydride ion from the substrate to the quinone, followed by a proton transfer from the resulting cationic intermediate to the hydroquinone anion. ${ }^{25}$ Based on this probable mechanism, we suggest the three pathways shown in Scheme 4 to justify the formation of the compounds we obtained. The rearrangement of chlorin I to porphyrin II is followed by a hydride abstraction at a benzylic-type position affording the "benzylic" carbocation III. This intermediate is then deprotonated to IV, which by a new dehydrogenation process affords the products 6a and $\mathbf{9}$ (path A). Compounds 7a and $\mathbf{1 0}$ are probably formed by the nucleophilic attack of the "benzylic" carbocation by the adjacent phenyl ring (at the ortho position) ${ }^{26}$ followed by a dehydrogenation process (path B). Nucleophilic attack on the "benzylic" carbocation III by water ${ }^{27}$ affords the hydroxylated derivatives $\mathbf{8}$ and $\mathbf{1 1}$ (path C). The formation of 7a via acid treatment of derivative $\mathbf{8}$ can be justified by the alcohol dehydration leading to the benzylic cation III followed by path B. It is worth pointing out that attempted synthesis of compound $\mathbf{1 0}$ by acid treatment of the hydroxylated derivative $\mathbf{1 1}$ resulted in an inseparable complex mixture. 


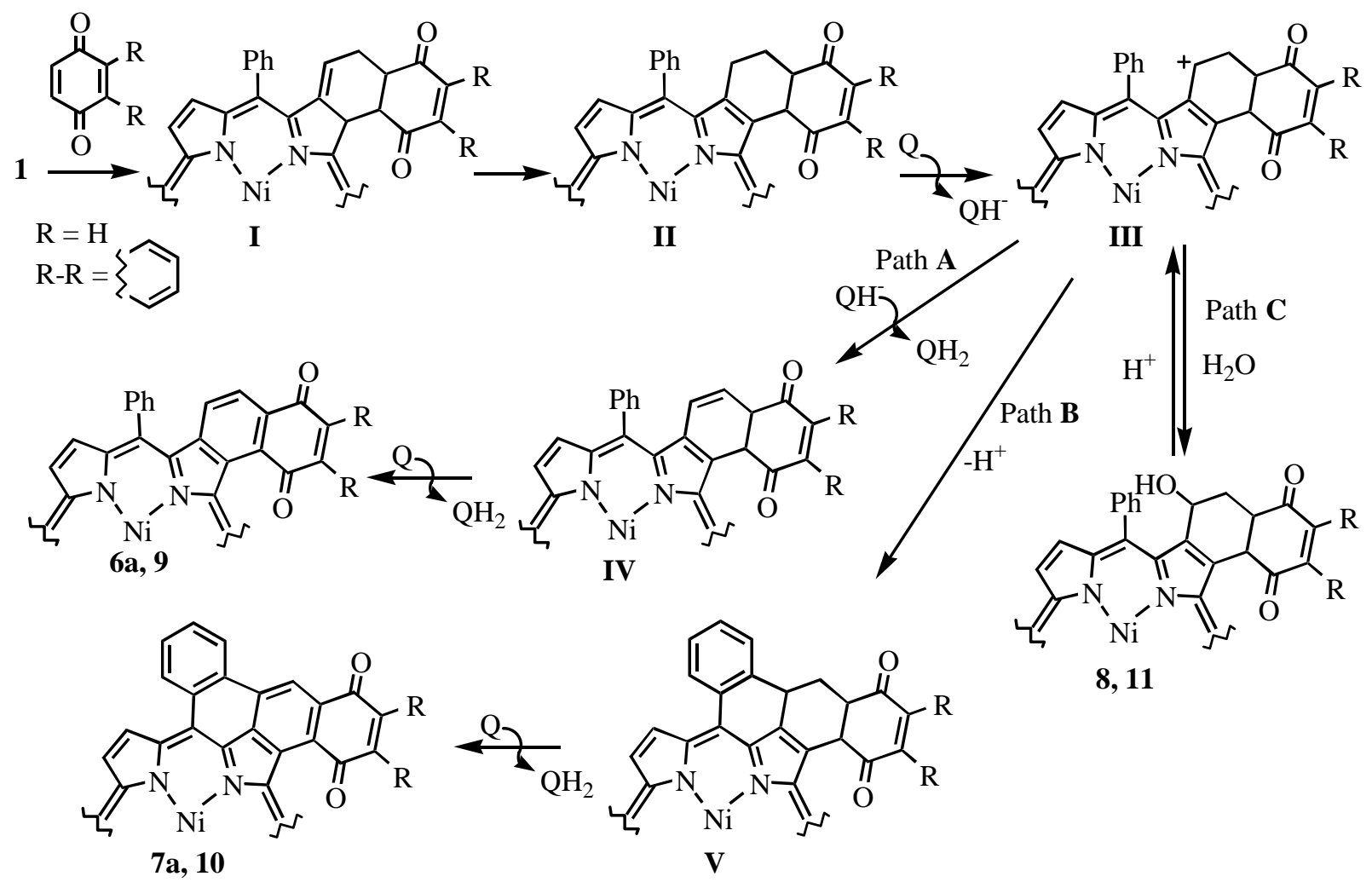

\section{Scheme 4}

\section{Experimental Section}

General Procedures. The UV-Vis spectra were recorded in chloroform solution on an Uvikon 922 Instruments spectrophotometer. The NMR spectra were recorded on a Bruker AMX 300 spectrometer. Deuterated chloroform was used as solvent and TMS as internal reference. All chemical shifts are expressed in parts per million (ppm) relative to TMS. ${ }^{1} \mathrm{H}$ - Assignments were made using 2D COSY and NOESY (mixing time of $800 \mathrm{~ms}$ ) experiments, while ${ }^{13} \mathrm{C}$ assignments were made using 2D HETCOR experiments as well as one-dimensional selective INEPT $^{28}$ (long-range $\mathrm{C} / \mathrm{H}$ coupling constants were optimized to $7 \mathrm{~Hz}$ ). Mass spectra were recorded on a VG AutoSpec Q spectrometer using 3-nitrobenzyl alcohol as matrix. Preparative thin layer chromatography (TLC) was carried out on 20 x $20 \mathrm{~cm}$ glass plates coated with silica gel (1 mm thick). Reactions were monitored by TLC and UV-visible spectra. Reagents and solvents were obtained from commercial suppliers and used without further purification unless stated otherwise. Petroleum refers to the fraction boiling at $40-60{ }^{\circ} \mathrm{C}$. Nickel(II)- 2-vinyl5,10,15,20-tetraphenylporphyrin 1 was synthesized according to a literature procedure. ${ }^{29}$ 
Reaction of porphyrin 1 with 1,4-naphthoquinone. Porphyrin 1 (5.4 mg, 7,8 $\mu \mathrm{mol}$ ) and 1,4naphthoquinone $(6.1 \mathrm{mg}, 38.6 \mu \mathrm{mol})$ were dissolved in dry toluene $(0.5 \mathrm{~mL})$ and the resulting solution was heated at reflux for $36 \mathrm{~h}$ under a nitrogen atmosphere. The resulting mixture was submitted to preparative TLC using toluene as eluent; porphyrin 1 (1.8 mg, 34\% recovered), anthra[1,2-b]porphyrin 6a (1.0 mg, 24\% yield), the polycyclic porphyrin derivative 7a (1.0 mg, 24\% yield), and the hydroxylated porphyrin 8 (0.9 mg, 21\% yield), were thus obtained. The yields were calculated based on the reacted porphyrin 1 .

6a. ${ }^{1} \mathrm{H}-\mathrm{NMR}\left(300 \mathrm{MHz}, \mathrm{CDCl}_{3}\right.$ ): $\delta$ 8.73, 8.68 and 8.62 (3d, $J=5.0 \mathrm{~Hz}, 3 \mathrm{H}, \mathrm{H}-18, \mathrm{H}-17$ and H7 or H-8), 8.54 and 8.52 (AB, $J=4.3 \mathrm{~Hz}, 2 \mathrm{H}, \mathrm{H}-12$ and $\mathrm{H}-13$ ), 8.29 (d, $J=8.5 \mathrm{~Hz}, 1 \mathrm{H}, \mathrm{H}-2^{\prime}$ ), 8.18 (d, $J=7,7$ Hz, 1H, H-4'), 8.17 (d, $J=5.0 \mathrm{~Hz}, 1 \mathrm{H}, \mathrm{H}-8$ or H-7), 8.02-7.53 (m, 21H, Ph-H and H-7'), 7.33 (d, $J=8.5 \mathrm{~Hz}, 1 \mathrm{H}, \mathrm{H}-1^{\prime}$ ), 7.07-7.13 (m, 2H, H-6' and H-5'). UV-Vis $\left(\mathrm{CHCl}_{3}\right)$ $\lambda_{\max }(\log \varepsilon) 437$ (4.95), 565 (3.94) nm. MS-FAB ${ }^{+} \mathrm{m} / \mathrm{z}$ for $\mathrm{C}_{56} \mathrm{H}_{33} \mathrm{~N}_{4} \mathrm{O}_{2} \mathrm{Ni}(\mathrm{M}+\mathrm{H})^{+} 851$.

7a. ${ }^{1} \mathrm{H}-\mathrm{NMR}\left(300 \mathrm{MHz}, \mathrm{CDCl}_{3}\right.$ ): $\delta 9.77$ (s, 1H, H-2'), 9.33 (d, $J=5.0 \mathrm{~Hz}, 1 \mathrm{H}, \mathrm{H}-18$ ), 9.05 (d, $J$ = $7.7 \mathrm{~Hz}, 1 \mathrm{H}, \mathrm{H}-3$ '’), 8.72 (d, $J=5.0 \mathrm{~Hz}, 1 \mathrm{H}, \mathrm{H}-17$ ), 8.61 (d, $J=6.4 \mathrm{~Hz}, 1 \mathrm{H}, \mathrm{H}-6$ ') $), 8.59$ (d, $J=$ $5.0 \mathrm{~Hz}, 1 \mathrm{H}, \mathrm{H}-7$ or H-8), 8.52 and 8.47 (AB, $J=4.9 \mathrm{~Hz}, 2 \mathrm{H}, \mathrm{H}-12$ and $\mathrm{H}-13$ ), 8.37 (d, $J=7.5$ Hz, 1H, H-4'), 8.21 (d, $J=5.0$ Hz, 1H, H-8 or H-7), 8.05 (d, $J=7.4$ Hz, 1H, 5-Ph- o-H), 7.927.61 (m, 17H, Ph-H, H-5', H-4', H-7', H-6' and H-5'), 7.34-7.17 (m, 2H, 5-Ph- m-H). ${ }^{13} \mathrm{C}-$ NMR (75 MHz, $\mathrm{CDCl}_{3}$ ): $\delta 120.1$ (C-2’), 120.9, 121.4, 121.9, 125.3 (C-3’’), 125.8, 126.3, 126.7 (C-4'), 126.9, 127.0, 127.1, 127.9, 128.0, 128.1, 128.5, 128.8, 129.1 (C-5'’), 129,2, 129.9, 130.2, 130.5, 131.4, 131.6, 132.0 (5-Ph -o-C), 132.1 (C-18, C-12, C-13), 132.2, 132.5 and 132.6 (C-7 and C-8), 132.7, 132.8, 133.3 (C-4’'), 133.5, 133.6, 134.3 (C-7’a), 134.6, 135.0 (C-17), 135.2 (C-6’’), 137.6, 138.3, 138.8, 139.2, 139.85, 139.9, 140.6, 141.1, 141.9, 142.4, 142.5, 146.8, 181.7 (C-8'), 184.7 (C-3’). UV-Vis $\left(\mathrm{CHCl}_{3}\right) \lambda_{\max }$ (log $\left.\varepsilon\right) 448$ (4.53), 593 (3.51), 644 (3.54) nm. MS-FAB ${ }^{+} \mathrm{m} / \mathrm{z}$ for $\mathrm{C}_{56} \mathrm{H}_{30} \mathrm{~N}_{4} \mathrm{O}_{2} \mathrm{Ni}\left(\mathrm{M}^{+}\right) 848$.

8. ${ }^{1} \mathrm{H}-\mathrm{NMR}\left(300 \mathrm{MHz}, \mathrm{CDCl}_{3}\right.$ ): $\delta 8.71$ and $8.68(\mathrm{AB}, J=5.0 \mathrm{~Hz}, 2 \mathrm{H}, \beta-\mathrm{H}), 8.55(\mathrm{~d}, J=5.0 \mathrm{~Hz}$, $1 \mathrm{H}, \beta-\mathrm{H}), 8.64-8.60$ (m, 3H, $\beta-\mathrm{H}$ ), 8.39-8.37 (m, 1H, H-4'), 8.07-7.13 (m, 23H, Ph-H, H-7', H6', H-5'), 5.14 (dt, $J=2.6,3.7$ Hz, 1H, H-1'), 4.45 (d, $J=5.4$ Hz, 1H, H-8'a), 4.00 (ddd, $J=2.6$, 5.4, 13.7 Hz, 1H, H-2’a), 2.23 (dt, $J=2.6,13.6 \mathrm{~Hz}, 1 \mathrm{H}, \mathrm{H}-2$ '), 1.97 (ddd, $J=3.7,13.6,13.7 \mathrm{~Hz}$, $1 \mathrm{H}, \mathrm{H}-2^{\prime}$ ), 1.85 (d, $\left.J=3.7 \mathrm{~Hz}, 1 \mathrm{H}, \mathrm{OH}\right) .{ }^{13} \mathrm{C}-\mathrm{NMR}\left(75 \mathrm{MHz}, \mathrm{CDCl}_{3}\right) \delta 34.8(C-2$ '), 44.9 (C2’a), 50.1 (C-8'a), 62.0 (C-1'), 116.1, 117.7, 119.1, 119.3, 126.6, 127.0, 127.2, 127.6, 127.8, 128.0, 128.9, 132.2, 132.25, 132.3, 132.65, 132.7, 133.6, 133.8, 134.2, 136.4, 137.8, 138.4, 139.3, 140.2, 140.3, 140.6, 140.8, 142.0, 142.2, 142.36, 142.4, 143.0, 143.2, 143.3, 197.2 (C-8'), 198.9 (C-3'). UV-Vis $\left(\mathrm{CHCl}_{3}\right) \lambda_{\max }(\log \varepsilon) 420$ (5.09), 536 (3.93) nm. MS-FAB ${ }^{+} \mathrm{m} / \mathrm{z}$ for $\mathrm{C}_{56} \mathrm{H}_{36} \mathrm{~N}_{4} \mathrm{O}_{3} \mathrm{Ni}\left(\mathrm{M}^{+}\right) 870$.

Conversion of compound 8 into 7a. Compound 8 (0.9 mg) was stirred for 10 minutes with a $10 \%$ mixture of trifluoroacetic acid in chloroform $(1 \mathrm{~mL})$. The color of the solution changed from red to brown. The mixture was then neutralized with saturated aq. $\mathrm{Na}_{2} \mathrm{CO}_{3}$ and extracted with dichloromethane $(3 \times 5 \mathrm{~mL})$. The organic layer was washed with water, dried $\left(\mathrm{Na}_{2} \mathrm{SO}_{4}\right)$ and the solvent was partially evaporated. The resulting solution was purified by preparative TLC, using dichloromethane/petroleum (1:2) as eluent, to afford pure 7a (0.8 mg, 85\% yield). 
Demetallation of compound 6a. Compound 6a was treated with a $10 \%$ mixture of sulfuric acid in trifluoroacetic acid at room temperature. The reaction was monitored by UV-Vis spectroscopy. When the demetallation was complete, chloroform was added and the reaction mixture was neutralized with saturated aqueous $\mathrm{Na}_{2} \mathrm{CO}_{3}$. The organic layer was washed with water, dried $\left(\mathrm{Na}_{2} \mathrm{SO}_{4}\right)$ and evaporated to dryness. Compound $\mathbf{6 b}$ was obtained in quantitative yield. ${ }^{1} \mathrm{H}$ - NMR (300 MHz, $\left.\mathrm{CDCl}_{3}\right): \delta 8.84(\mathrm{~d}, J=5.1 \mathrm{~Hz}, 1 \mathrm{H}, \beta-\mathrm{H}), 8.81(\mathrm{~d}, J=4.8 \mathrm{~Hz}, 1 \mathrm{H}, \beta-$ H), 8.76 (d, $J=5.1 \mathrm{~Hz}, 1 \mathrm{H}, \beta-\mathrm{H}), 8.73$ (d, $J=4.8 \mathrm{~Hz}, 1 \mathrm{H}, \beta-\mathrm{H}), 8.63$ (AB, $J=4.2 \mathrm{~Hz}, 2 \mathrm{H}, \mathrm{H}-12$ and H-13), 8.51 (d, $J=6.6 \mathrm{~Hz}, 1 \mathrm{H}, \mathrm{H}-4^{\prime}$ ), 8.31 (d, $J=8.4 \mathrm{~Hz}, 1 \mathrm{H}, \mathrm{H}-2$ '), 8.11-7.69 (m, $21 \mathrm{H}$, Ph-H, H-7') 7.36 (d, $J=8.4$ Hz, 1H, H-1'), 7.18-7.13 (m, 2H, H-6' and H-5'), -2.04 (s, 2H, NH). UV-Vis $\left(\mathrm{CHCl}_{3}\right) \lambda_{\max }(\log \varepsilon) 443(5,13), 539(4,01), 619(3,64), 685(3,39) \mathrm{nm}$. MS-HRFAB ${ }^{+} \mathrm{m} / \mathrm{z}$ for $\mathrm{C}_{56} \mathrm{H}_{35} \mathrm{~N}_{4} \mathrm{O}_{2}(\mathrm{M}+\mathrm{H})^{+}$calculated, 795.2760; found, 795.2746.

Demetallation of compound $7 \mathbf{a}$. Compound $\mathbf{7 b}$ was obtained in quantitative yield by the procedure described for the demetallation of 6a. ${ }^{1} \mathrm{H}-\mathrm{NMR}\left(300 \mathrm{MHz}, \mathrm{CDCl}_{3}\right) \delta 9.93(\mathrm{~s}, 1 \mathrm{H}, \mathrm{H}-$ 2'), 9.72 (d, $J=4.8 \mathrm{~Hz}, 1 \mathrm{H}, \mathrm{H}-18$ ), 9.23 (d, $J=7.2 \mathrm{~Hz}, 1 \mathrm{H}, \mathrm{H}-3$ ') ), 9.12 (d, $J=7.7 \mathrm{~Hz}, 1 \mathrm{H}, \mathrm{H}-$ 6'’), 8.91 (d, $J=4.8 \mathrm{~Hz}, 1 \mathrm{H}, \mathrm{H}-17$ ), 8.77 (s, 2H, H-12 and H-13), 8.68-8.53 (m, 4H, H-7, H-8 and 5-Ar- $o-\mathrm{H}), 8.38$ (d, $J=7.1 \mathrm{~Hz}, 1 \mathrm{H}, \mathrm{H}-4$ '), 8.07-7.61 (m, 18H, Ph-H, H-5', , H-4', , H-7', H6' and $\mathrm{H}-5$ '), $-1,06$ (s, $1 \mathrm{H}, \mathrm{NH}),-1,28$ (s, 1H, NH). UV-Vis $\left(\mathrm{CHCl}_{3}\right) \lambda_{\max }(\log \varepsilon) 460$ (4.51), 629 (3.45), 700 (3.31). MS-HRFAB ${ }^{+} \mathrm{m} / \mathrm{z}$ for $\mathrm{C}_{56} \mathrm{H}_{33} \mathrm{~N}_{4} \mathrm{O}_{2}(\mathrm{M}+\mathrm{H})^{+}$calculated, 793.2604; found, 793.2605.

Reaction of porphyrin 1 with 1,4-benzoquinone. Porphyrin 1 (11.1 mg, $16 \mu \mathrm{mol})$ was dissolved in dry toluene $(1 \mathrm{~mL})$ and 1,4-benzoquinone (17.0 mg, $160 \mu \mathrm{mol})$ was added. The resulting mixture was heated at reflux for $65 \mathrm{~h}$ under nitrogen. After cooling to RT, the reaction mixture was diluted with dichloromethane $(25 \mathrm{~mL})$ washed with aq. $\mathrm{NaOH}(3 \times 25 \mathrm{~mL})$. The organic layer was washed with water, dried $\left(\mathrm{Na}_{2} \mathrm{SO}_{4}\right)$ and part of the solvent was evaporated. Purification by preparative TLC using a 3:1 mixture of dichloromethane/petroleum as eluent afforded porphyrin 1 (2.5 mg, 23\% recovered), naphtho[1,2-b]porphyrin 9 (0.8 mg, 8\% yield), polycyclic porphyrin 10 (0.4 mg, 4\% yield), the hydroxylated derivative 11 (4.4 mg, 50\%), and other minor fractions, which were discarded. The yields were calculated based on the reacted porphyrin 1.

9. ${ }^{1} \mathrm{H}-\mathrm{NMR}\left(300 \mathrm{MHz}, \mathrm{CDCl}_{3}\right.$ ) $\delta 8.72$ and 8.67 (2d, $J=4.9 \mathrm{~Hz}, 2 \mathrm{H}, \mathrm{H}-18$ and H-17), 8.63 (d, $J$ $=5.0 \mathrm{~Hz}, 1 \mathrm{H}, \mathrm{H}-7$ or H-8), 8.53 and 8.51 (AB, $J=4.3 \mathrm{~Hz}, 2 \mathrm{H}, \mathrm{H}-12$ and $\mathrm{H}-13), 8.25$ (d, $J=5.0$ Hz, 1H, H-8 or H-7), 8.06 (d, $J=8.5$ Hz, 1H, H-2'), 7.97-7.54 (m, $20 \mathrm{H}, \mathrm{Ph}-\mathrm{H}), 7.28$ (d, $J=8.5$ $\mathrm{Hz}, 1 \mathrm{H}, \mathrm{H}-1^{\prime}$ ), 6.67 and 6.24 (2d, $J=10.2 \mathrm{~Hz}, 2 \mathrm{x} 1 \mathrm{H}, \mathrm{H}-4$ ' and $\mathrm{H}-5$ '). UV-Vis $\left(\mathrm{CHCl}_{3}\right) \lambda_{\max }$ (log ع), 432 (5.20), 553 (4.04) nm. MS-HRFAB ${ }^{+} \mathrm{m} / \mathrm{z}$ for $\mathrm{C}_{52} \mathrm{H}_{31} \mathrm{~N}_{4} \mathrm{O}_{2} \mathrm{Ni}(\mathrm{M}+\mathrm{H})^{+}$calculated, 801.1800; found, 801.1805.

10. ${ }^{1} \mathrm{H}-\mathrm{NMR}\left(300 \mathrm{MHz}, \mathrm{CDCl}_{3}\right.$ ) $\delta 9.62$ (s, 1H, H-2'), 9.40 (d, $\left.J=4.9 \mathrm{~Hz}, 1 \mathrm{H}, \mathrm{H}-18\right), 9.10$ (d, $J$ $=7.5 \mathrm{~Hz}, 1 \mathrm{H}, \mathrm{H}-3$ '’), 8.80 (d, $J=4.9 \mathrm{~Hz}, 1 \mathrm{H}, \mathrm{H}-17$ ), 8.70 (d, $J=7.2 \mathrm{~Hz}, 1 \mathrm{H}, \mathrm{H}-6$ '’), 8.61 and 8.31 (2d, $J=4.9 \mathrm{~Hz}, 2 \mathrm{H}, \mathrm{H}-7$ and $\mathrm{H}-8$ ), 8.52 and 8.47 (AB, $J=4.9 \mathrm{~Hz}, 2 \mathrm{H}, \mathrm{H}-12$ and H-13), 8.09 (d, $J=7.5 \mathrm{~Hz}, 1 \mathrm{H}, 5-\mathrm{Ph}-\mathrm{O}-\mathrm{H}), 7.92$ (t, $J=7.2 \mathrm{~Hz}, 1 \mathrm{H}, \mathrm{H}-5$ '’), 7.87-7.54 (m, 15H, H-4’', Ph-H), 6.92 and 6.47 (2d, $J=10.4 \mathrm{~Hz}, 2 \times 1 \mathrm{H}, \mathrm{H}-4^{\prime}$ and H-5'). UV-Vis $\left(\mathrm{CHCl}_{3}\right) \lambda_{\max }(\log \varepsilon) 446$ 
(4.97), 546 (3.76), 641 (3.54) nm. MS-HRFAB ${ }^{+} \mathrm{m} / \mathrm{z}$ for $\mathrm{C}_{52} \mathrm{H}_{29} \mathrm{~N}_{4} \mathrm{O}_{2} \mathrm{Ni}(\mathrm{M}+\mathrm{H})^{+}$calculated, 799.1644; found, 799.1611.

11. ${ }^{1} \mathrm{H}-\mathrm{NMR}\left(300 \mathrm{MHz}, \mathrm{CDCl}_{3}\right.$ ) $\delta$ 8.72-8.53 (m, 6H, H-7, H-8, H-12, H-13, H-17 and H-18), 8.40 (d, $J=7.5 \mathrm{~Hz}, 1 \mathrm{H}, 5-\mathrm{Ar}-o-\mathrm{H}), 8.09$ (d, $J=7.2 \mathrm{~Hz}, 1 \mathrm{H}, 15-\mathrm{Ph}-o-\mathrm{H}), 7.97-7.39$ (m, $18 \mathrm{H}$, Ph-H), 6.63 (d, $J=10.5$ Hz, 1H, H-4'), 6.51 (d, $J=10.5$ Hz, 1H, H-5'), 5.13 (dt, $J=2.9,3.7$ Hz, 1H, H-1'), 4.33 (d, $J=5.5$ Hz, 1H, H-6'a), 3.84 (ddd, $J=2.9,5.5,13.6$ Hz, 1H, H-2'a), 2.18 (dt, $J=2.9,13.4 \mathrm{~Hz}, 1 \mathrm{H}, \mathrm{H}-2$ ') 1.90 (ddd, $J=3.7,13.4,13.6 \mathrm{~Hz}, 1 \mathrm{H}, \mathrm{H}-2$ '), 1.79 (d, $J=2.9 \mathrm{~Hz}, 1 \mathrm{H}$, $\mathrm{OH}) .{ }^{13} \mathrm{C}-\mathrm{NMR}\left(75 \mathrm{MHz}, \mathrm{CDCl}_{3}\right) \delta 34.9$ (C-2’), 44.7 (C-2’a), 49.8 (C-6’a), 61.7 (C-1'), 116.0, 117.5, 119.1, 119.3, 126.4, 127.0, 127.2, 127.3, 127.7, 127.8, 128.6, 129.0, 132.3, 132.4, 132.6, 132.7, 133.6, 134.0, 137.6, 138.0, 138.1, 138.3 (C-5'), 140.2, 140.6, 141.4 (C-4'), 142.1, 142.2, 142.4, 142.5, 142.9, 143.2, 198.0 (C-6'), 201.1 (C-3’). UV-Vis $\left(\mathrm{CHCl}_{3}\right) \lambda_{\max }(\log \varepsilon) 422$ (5.31), 537 (4.20) nm. MS-FAB ${ }^{+} \mathrm{m} / \mathrm{z}$ for $\mathrm{C}_{52} \mathrm{H}_{34} \mathrm{~N}_{4} \mathrm{O}_{3} \mathrm{Ni}\left(\mathrm{M}^{+}\right) 820$.

\section{Conclusions}

The Diels-Alder reaction of Ni(II)-2-vinyl-5,10,15,20-tetraphenylporphyrin with 1,4naphthoquinone and 1,4-benzoquinone affords mixtures of compounds resulting from dehydrogenation, hydroxylation or cyclization reactions in the initial adduct. The formation of these products can be justified considering the formation of a common intermediate, the benzylic-type carbocation III.

\section{Acknowledgements}

Thanks are due to the University of Aveiro and to the "Fundação para a Ciência e Tecnologia" for funding the Organic Chemistry Research Unit.

\section{References}

1. Cavaleiro, J. A. S.; Neves, M. G. P. M. S.; Tomé, A. C. ARKIVOC 2003, (xiv), 107.

2. Inhoffen, H. H.; Brockmann, H.; Bliesener, K.-M. Liebigs Ann. 1969, 730, 173.

3. DiNello, R. K.; Dolphin, D. J. Org. Chem. 1980, 45, 5196.

4. Morgan, A. R.; Pangka, V. S.; Dolphin, D. J. Chem. Soc., Chem. Commun. 1984, 1047.

5. Pangka, V. S.; Morgan, A. R.; Dolphin, D. J. Org. Chem. 1986, 51, 1094.

6. Yon-Hin, P.; Wijesekera, T. P.; Dolphin, D. Tetrahedron Lett. 1989, 30, 6135.

7. Faustino, M. A. F.; Neves, M. G. P. M. S.; Vicente, M. G. H.; Silva, A. M. S.; Cavaleiro, J. A. S. Tetrahedron Lett. 1996, 37, 3569.

8. Faustino, M. A. F.; Neves, M. G. P. M. S.; Silva, A. M. S.; Cavaleiro, J. A. S. Chimia 1997, $51,472$. 
9. Faustino, M. A. F.; Neves, M. G. P. M. S.; Silva, A. M. S.; Cavaleiro, J. A. S., $12^{\text {th }}$ International Conference on Organic Synthesis (ICOS-12), Poster 496, Venice, 1998.

10. Faustino, M. A. F. Ph.D. Thesis, University of Aveiro, 1999.

11. Gust, D.; Moore, T. In The Porphyrin Handbook, Kadish, K. M.; Smith, K. M.; Guilard, R., Eds; Academic Press: San Diego, 2000; Vol. 8, p 153.

12. (a) Wasielewski, M. R. Chem. Rev. 1992, 92, 435. (b) Kurreck, H.; Huber, M. Angew. Chem., Int. Ed. 1995, 34, 849.

13. (a) Shi, X.; Amin, R.; Liebeskind, L. S. J. Org. Chem. 2000, 65, 1650. (b) Shi, X.; Liebeskind, L. S. J. Org. Chem. 2000, 65, 1665.

14. (a) Speck, M.; Kurreck, H.; Senge, M. O. Eur. J. Org. Chem. 2000, 2303. (b) Wiehe, A.; Senge, M. O.; Schäfer, A.; Speck, M.; Tannert, S.; Kurreck, H.; Röder, B. Tetrahedron 2001, 57, 10089.

15. (a) Springer, J.; Kodis, G.; Garza, L.; Moore, A. L.; Moore, T. A. Gust, D. J. Phys. Chem. A 2003, 107, 3567. (b) Kang, Y. K.; Rubtsov, I. V.; Iovine, P. M.; Chen, J.; Therien, M. J. J. Am. Chem. Soc. 2002, 124, 8275.

16. Mehta, G.; Muthusamy, S.; Maiya, B. G.; Arounaguiri, S. Tetrahedron Lett. 1997, 38, 7125.

17. Okamoto, K.; Fukuzumi, S. J. Am. Chem. Soc. 2004, 126, 13922.

18. (a) D’Souza, F.; Deviprasad, G. R. J. Org. Chem. 2001, 66, 4601. (b) D’Souza, F.; Deviprasad, G. R.; Hsieh, Y.-Y. Chem. Commun. 1997, 533.

19. Grennberg, H.; Faizon, S.; Bäckvall, J. E. Angew. Chem., Int. Ed. 1993, 32, 263.

20. (a) Crossley, M. J.; Johnston, L. A. Chem. Commun. 2002, 1122. (b) Antolovich, M.; Keyte, P. J.; Oliver, A. M.; Paddon-Row, M. N.; Kroon, J.; Verhoeven, J. W.; Jonker, S. A.; Warman, J. M. J. Phys. Chem. 1991, 95, 1933.

21. (a) Wasielewski, M. R.; Johnson, D. G.; Svec, W. A. In Supramolecular Photochemistry; Balzani, V., Ed.; D. Reidel: Amsterdam, 1987; p 255. (b) Knapp, S.; Dhar, T. G. M.; Albaneze, J.; Gentemann, S.; Potenza, J. A.; Holten, D.; Schugar, H. J. J. Am. Chem. Soc. 1991, 113, 4010.

22. (a) Hayashi, T.; Takimura, T.; Hitomi, Y.; Ohara, T.; Ogoshi, H. J. Chem. Soc., Chem. Commun. 1995, 545. (b) Hayashi, T.; Takimura, T.; Hitomi, Y.; Ohara, T.; Ogoshi, H. J. Chem. Soc., Chem. Commun. 1995, 2503.

23. Matsumoto, K.; Kimura Heterocycl. Commun. 2000, 6, 31.

24. Matsumoto, K.; Kimura, S.; Morishita, T.; Misumi, Y.; Hayashi, N. Synlett 2000, 233.

25. Becher, H-D. In, The Chemistry of the Quinoid Compounds - Part 1; Patai, S., Ed.; Jerusalem, 1974; p 335.

26. Faustino, M. A. F.; Neves, M. G. P. M. S.; Vicente, M. G. H.; Silva, A. M. S.; Cavaleiro, J. A. S. Tetrahedron Lett. 1995, 36, 5977.

27. Eklund, P. C.; Sjöholm R.E. Tetrahedron 2003, 59, 4515.

28. Bax, A. J. Magn. Reson. 1984, 57, 314.

29. Callot, H. Tetrahedron 1973, 29, 899. 